\title{
Comparison of Lipase Production by Enterococcus faecium MTCC 5695 and Pediococcus acidilactici MTCC 11361 Using Fish Waste as Substrate: Optimization of Culture Conditions by Response Surface Methodology
}

\author{
Vrinda Ramakrishnan, ${ }^{1}$ Louella Concepta Goveas, ${ }^{1}$ \\ Bhaskar Narayan, ${ }^{2}$ and Prakash M. Halami ${ }^{1}$ \\ ${ }^{1}$ Department of Food Microbiology, Central Food Technological Research Institute (CSIR), Mysore 570 020, India \\ ${ }^{2}$ Department of Meat, Fish \& Poultry Technology, Central Food Technological Research Institute (CSIR), Mysore 570 020, India
}

Correspondence should be addressed to Bhaskar Narayan; bhaskar@cftri.res.in and Prakash M. Halami; prakashalami@cftri.res.in

Received 21 June 2012; Accepted 22 July 2012

Academic Editors: H. S. Garcia, N. Labrou, C. D. Murphy, and H. Stamatis

\begin{abstract}
Copyright ( 2013 Vrinda Ramakrishnan et al. This is an open access article distributed under the Creative Commons Attribution License, which permits unrestricted use, distribution, and reproduction in any medium, provided the original work is properly cited.

A medium using fish waste as substrate was designed for production of lipase by Enterococcus faecium MTCC 5695 and Pediococcus acidilactici MTCC 11361. Medium components and culture conditions (fish waste protein hydrolysate (FWPH) concentration, fish waste oil (FWO) concentration, $\mathrm{pH}$, temperature, and fermentation time) which affect lipase production were screened using factorial ( 5 factors $* 2$ levels) design of which FWPH concentration, FWO concentration, and fermentation time showed significance $(P<0.05)$. The levels of these factors were optimized further by Box-Behnken design using response surface methodology (RSM). Optimized conditions were found to be $5 \% \mathrm{v} / \mathrm{v}$ FWO, $0.15 \mathrm{mg} / \mathrm{mL}$ FWPH and $24 \mathrm{~h}$ of fermentation time for MTCC 5695, and 4\% v/v FWO, $0.15 \mathrm{mg} / \mathrm{mL}$ FWPH and $24 \mathrm{~h}$ of fermentation for MTCC 11361, which were further validated. Under optimized conditions, MTCC 5695 and MTCC 11361 showed 3.15- (543.63 to $1715 \mathrm{U} / \mathrm{mL})$ and 2.3- $(214.74$ to $493 \mathrm{U} / \mathrm{mL})$ fold increase in lipase production, respectively, as compared to unoptimized conditions.
\end{abstract}

\section{Introduction}

Lipases (triacylglycerol acylhydrolases EC 3.1.1.3) are a class of serine hydrolases which catalyze the hydrolysis of triglycerides to glycerol and free fatty acids over oil-water interface [1]. In addition, lipases catalyze the hydrolysis and transesterification of other esters as well as the synthesis of esters and exhibit enantioselective properties [2]. These unique properties of lipases make them a very important enzyme of industrial significance. Lipases are used in chemical processing, dairy industries for improvement of flavour, paper industries, oleochemical industries, pharmaceuticals, synthesis of surfactants, detergent industries, leather industries, and polymer synthesis $[3,4]$.
Lipases are produced by plants, animals, and microbes but only microbial lipases are found to be industrially important since they are diversified in their enzymatic properties and substrate specificity [5]. Bacterial lipases that are of commercial importance are obtained from Achromobacter, Alcaligenes, Arthrobacter, Bacillus, Burkholderia, Chromobacterium, and Pseudomonas [6, 7].

Lactic Acid Bacteria (LAB) are generally considered to be weakly lipolytic, as compared to other groups of microorganisms. The lipolytic activity by LAB plays an important role in the determination of special aroma of different cheeses $[8,9]$. Since they are considered as generally recognised as safe (GRAS), they are used extensively as starter cultures in food and feed industries [10]. Although there are reports on 
lactic acid bacterial lipase production [11-13], they are fewer in comparison to other microorganisms like Bacillus.

Most research is now focused on the use of waste residues generated by industries as inexpensive substrates for microbial growth and metabolite production. Fish processing industries generate around 63.6 million metric tons (MMT) in which 2.8 MMT of waste are generated in India alone [14]. These wastes are a rich source of biomolecules such as lipids, proteins, chitin, collagen, minerals, and vitamins that can be recovered and utilized [15]. The lipids and proteins are extracted from the fish wastes either by addition of enzymes or by fermentation with LAB [16]. Lactic acid bacterial fermentation has been used for recovery of oil from fish viscera and also for extraction of proteins from shrimp waste and leather industry waste $[15,17,18]$. These lipidic carbon and nitrogen rich sources can be used as ample substrates for lipase production by LAB. However, these carbon and nitrogen supplements used must be optimized for maximal lipase production.

The most challenging task in optimization is the presence of interactive effects of media components and culture conditions. Response Surface Methodology (RSM) is a collection of statistical and mathematical techniques useful for developing, improving, and optimizing processes in which a response of interest is influenced by several variables and the objective is to optimize this response [19]. It defines the effect of independent variables, alone or in combination, on the processes and generates a mathematical model that describes the process [20].

In the present study, fish waste was used to design a medium for lipase production by Enterococcus faecium MTCC 5695 and Pediococcus acidilactici MTCC 11361. The significant parameters (media components and cultural conditions) on lipase production were identified using a factorial design and optimized using a Box-Behnken design. To the very best of our knowledge, there are no reports on the optimization of lipase production by LAB from fish waste by RSM.

\section{Materials and Methods}

2.1. Substrates and Chemicals. Fresh water fish visceral waste devoid of air bladder was collected from local fish markets in Mysore, India. Enterococcus faecium NCIM5335 (EF-35) used for extraction of fish oil was obtained from institute collection centre. All microbiological media were procured from HiMedia (M/s Hi-Media, Mumbai, India). Para-nitrophenyl acetate $(p$-NPA) and $p$-nitrophenol were obtained from SRL (SRL chemicals, Bangalore, India). All other chemicals, solvents, and reagents used in the study were of analytical grade, unless otherwise mentioned.

2.2. Bacterial Strains and Inoculum Preparation. The lipaseproducing strains used in the present study were isolated from fish processing waste. They were identified by $16 \mathrm{~S}$ rDNA sequencing as Enterococcus faecium MTCC 5695 and Pediococcus acidilactici MTCC 11361 and deposited in National Culture Collection of Industrial Microorganisms,
TABLE 1: Composition of medium used for lipase production by MTCC 5695 and MTCC 11361.

\begin{tabular}{lc}
\hline Constituents & Amount $(\mathrm{g} / 100 \mathrm{~mL})$ \\
\hline Magnesium sulphate & 0.01 \\
Manganese sulphate & 0.005 \\
Dipotassium hydrogen phosphate & 0.2 \\
Sodium acetate & 0.5 \\
Ammonium citrate & 0.2 \\
Tween 80 & 0.1 \\
FWO $^{*}$ & $\mathrm{~A}^{\#}(\% \mathrm{v} / \mathrm{v})$ \\
FWPH $^{* *}$ & $\mathrm{~B}^{\#}(\mathrm{mg} / \mathrm{ml})$ \\
\hline
\end{tabular}

*As replacement for carbon source.

** As replacement for nitrogen source.

\# Added as per concentrations indicated in Tables 2 and 4 (protein concentration of FWPH: $33.53 \mathrm{mg} / \mathrm{mL}$ as estimated by Biuret's method).

FWO: fish waste oil; oil recovered from fermented fish processing waste.

FWPH: fish waste protein hydrolysates; obtained after fermentation of fish processing waste.

NCL, Pune. The strains were maintained as MRS glycerol stocks at $-20^{\circ} \mathrm{C}$ and subcultured periodically. The gene sequences of Enterococcus faecium MTCC 5695 and Pediococcus acidilactici MTCC 11361 are deposited in NCBI with accession numbers HQ005360 and submission ID 1554294.

2.3. Extraction of FWO and FWPH from Fish Waste. Extraction of FWO was done as per the procedure detailed in Rai et al. [15] with slight modifications. Fresh water fish visceral waste devoid of air bladder was subjected to homogenization in a Waring blender (Stephen Mill, UM5 Universal, Hong Kong). The uniformly homogenized fish viscera was steam cooked at $85^{\circ} \mathrm{C}$ for 10 minutes to inactivate the inherent enzymes and microflora, followed by fermentation for 72 hours using EF-35. The fermented mass was then centrifuged at $6000 \mathrm{rpm}$ for $20 \mathrm{~min}$. FWO separated out into the top layer followed by protein rich residue layer.

The protein hydrolysate was extracted from the protein rich residue layer as per Bhaskar et al. [21] with few modifications. The protein residue layer was extracted thrice with distilled water in the ratio $1: 1 \mathrm{w} / \mathrm{v}$. Protein extract obtained on centrifugation was subjected to lyophilisation to give FWPH, which was then dissolved in distilled water. The protein concentration was measured using Biuret's method [22].

2.4. Optimization Experiments. The medium used for optimization studies consisted of components as shown in Table 1.

2.4.1. Screening of Significant Parameters Affecting Lipase Production by Factorial Design. The effect of $\mathrm{pH}(X 1)$, temperature $\left(X 2,{ }^{\circ} \mathrm{C}\right)$, time $(X 3, \mathrm{~h}), \mathrm{FWPH}$ concentration $(X 4, \mathrm{mg} / \mathrm{mL})$, and FWO concentration $(X 5, \% \mathrm{v} / \mathrm{v})$ on lipase production by MTCC 5695 and MTCC 11361 was studied by a (5 factors $* 2$ levels) factorial design encompassing 32 runs (Table 2). Lipase activity $(Y)$ was determined as the response (dependent variable) and specifically designated as $Y_{a}$ and 
TABLE 2: Factorial design for screening of significant independent variables affecting lipase production with the observed lipase activity values.

\begin{tabular}{|c|c|c|c|c|c|c|}
\hline$X 1 \mathrm{pH}$ & $\begin{array}{c}X 2 \text { temp } \\
\left({ }^{\circ} \mathrm{C}\right)\end{array}$ & $\begin{array}{c}X 3 \text { time } \\
\text { (h) }\end{array}$ & $\begin{array}{c}X 4 \mathrm{FWPH} \\
(\mathrm{mg} / \mathrm{mL})\end{array}$ & $\begin{array}{c}X 5 \text { FWO } \\
(\% \mathrm{v} / \mathrm{v})\end{array}$ & $\begin{array}{c}Y_{a} \\
(\mathrm{U} / \mathrm{mL})\end{array}$ & $\begin{array}{c}Y_{b} \\
(\mathrm{U} / \mathrm{mL})\end{array}$ \\
\hline 5 & 37 & 24 & 0.1 & 1 & 645 & 97.33 \\
\hline 5 & 37 & 24 & 0.1 & 5 & 983 & 269.56 \\
\hline 5 & 37 & 24 & 0.2 & 1 & 865.976 & 73.54 \\
\hline 5 & 37 & 24 & 0.2 & 5 & 1428 & 391 \\
\hline 5 & 37 & 72 & 0.1 & 1 & 243.98 & 41.2 \\
\hline 5 & 37 & 72 & 0.1 & 5 & 1109.77 & 215.23 \\
\hline 5 & 37 & 72 & 0.2 & 1 & 639 & 51.823 \\
\hline 5 & 37 & 72 & 0.2 & 5 & 1208.67 & 287.45 \\
\hline 5 & 47 & 24 & 0.1 & 1 & 908.743 & 158 \\
\hline 5 & 47 & 24 & 0.1 & 5 & 1139.89 & 276 \\
\hline 5 & 47 & 24 & 0.2 & 1 & 1097 & 89.779 \\
\hline 5 & 47 & 24 & 0.2 & 5 & 1565.09 & 234 \\
\hline 5 & 47 & 72 & 0.1 & 1 & 367.8188 & 68.9 \\
\hline 5 & 47 & 72 & 0.1 & 5 & 890.098 & 213.856 \\
\hline 5 & 47 & 72 & 0.2 & 1 & 737.51 & 49 \\
\hline 5 & 47 & 72 & 0.2 & 5 & 1183 & 330 \\
\hline 7 & 37 & 24 & 0.1 & 1 & 410 & 89.12 \\
\hline 7 & 37 & 24 & 0.1 & 5 & 1430 & 274.33 \\
\hline 7 & 37 & 24 & 0.2 & 1 & 1123 & 121 \\
\hline 7 & 37 & 24 & 0.2 & 5 & 1603.45 & 409.66 \\
\hline 7 & 37 & 72 & 0.1 & 1 & 378 & 34.567 \\
\hline 7 & 37 & 72 & 0.1 & 5 & 967 & 208 \\
\hline 7 & 37 & 72 & 0.2 & 1 & 809.09 & 58.526 \\
\hline 7 & 37 & 72 & 0.2 & 5 & 1118 & 281 \\
\hline 7 & 47 & 24 & 0.1 & 1 & 1010 & 91.23 \\
\hline 7 & 47 & 24 & 0.1 & 5 & 1324 & 299 \\
\hline 7 & 47 & 24 & 0.2 & 1 & 1238.45 & 145.89 \\
\hline 7 & 47 & 24 & 0.2 & 5 & 1365.23 & 391.9 \\
\hline 7 & 47 & 72 & 0.1 & 1 & 733 & 89.98 \\
\hline 7 & 47 & 72 & 0.1 & 5 & 889 & 195 \\
\hline 7 & 47 & 72 & 0.2 & 1 & 900.23 & 96 \\
\hline 7 & 47 & 72 & 0.2 & 5 & 1203 & 310 \\
\hline
\end{tabular}

$X 1$ : pH; X2: temperature, ${ }^{\circ} \mathrm{C} ; X 3$ : time, hours; $X 4$ : FWPH concentration $(\mathrm{mg} / \mathrm{mL}) ; X 5$ : FWO concentration, \% v/v; $Y_{a}$ : lipase activity (U/mL) of MTCC 5695 ; $Y_{b}$ : lipase activity of MTCC 11361; FWPH: fish waste protein hydrolysates; FWO: fish waste oil.

$Y_{b}$ for lipase activities of MTCC 5695 and MTCC 11361, respectively. FWPH and FWO were added as per amounts indicated in Table 2. The most significant factors influencing lipase production by MTCC 5695 and MTCC 11361 were chosen to enhance lipase production by Box-Behnken design.

2.4.2. Box-Behnken Design. A Box-Behnken design for three factors encompassing 15 runs (Table 4) was applied for optimization of lipase production by MTCC 5695 and MTCC 11361. The factors namely FWO concentration $(X 1, \% \mathrm{v} / \mathrm{v})$, FWPH concentration $(X 2, \mathrm{mg} / \mathrm{mL})$, and time $(X 3, \mathrm{~h})$ were employed in three levels $(-1,0,+1)$. Lipase activity $(Y)$ was determined as the response (dependent variable). Lipase activities of MTCC 5695 and MTCC 11361 were designated as $Y_{1}$ and $Y_{2}$, respectively. FWPH and FWO were added as per amounts indicated in Table 4.

2.5. Lipase Assay. The optimization experiments were performed as presented in Tables 2 and 4 in $250 \mathrm{~mL}$ Erlenmeyer flasks containing $100 \mathrm{~mL}$ media. The experiments were performed in triplicates. The $\mathrm{pH}$ and temperature were maintained at 6.0 and $43^{\circ} \mathrm{C}$ (central values generated through factorial design), respectively. As per the time intervals indicated in Tables 2 and 4, sample aliquots were collected 
and centrifuged at $10,000 \mathrm{rpm}$ for $10 \mathrm{~min}$. Cell pellet was collected and sonicated in phosphate buffer ( $\mathrm{pH}$ 7.0) for complete lysis. The lysed cells were centrifuged and lipase assay was performed for the cell free extract.

Lipase activity was determined spectrophotometrically using $p$-NPA as the substrate as described by Wang et al. [23] with slight modifications. $300 \mu \mathrm{L}$ of cell supernatant and $900 \mu \mathrm{L}$ of acetonitrile : ethanol : phosphate buffer ( $\mathrm{pH} 6.8$ ) in ratio of $1: 4: 95$ was mixed with $800 \mu \mathrm{L}$ of $p$-NPA $(100 \mathrm{mM})$ in acetonitrile. This mixture was then incubated at $37^{\circ} \mathrm{C}$ for 15 minutes. The liberated $p$-nitrophenol was estimated at $408 \mathrm{~nm}$. One unit of lipase activity is defined as the amount of enzyme required to liberate one $\mu \mathrm{mol}$ of $p$-nitrophenol per minute under the standard assay conditions.

2.6. Statistical Analysis. The screening and optimization experiments were designed by STATISTICA software [24]. The data generated from the experiments were analyzed to obtain the optimized conditions by the same.

\section{Results and Discussion}

3.1. Selection of Substrate for Efficient Lipase Production by MTCC 5695 and MTCC 11361. Fish waste contains a rich source of both lipids and proteins and thereby can be applied as an efficient substrate for microbial growth and production of various metabolites $[16,25]$. Henceforth, this study aims at the use of fish waste as an effective alternative for the carbon and nitrogen sources present in media currently used for cultivation of LAB. In this study, the carbon and nitrogen sources in the commercial MRS medium were replaced with FWO and FWPH, respectively, as indicated in Table 1. FWO and FWPH helped in enhanced lipase production by both the organisms thereby acting as a replacement for carbon and nitrogen sources, respectively. FWO consists mainly of triacylglycerols that comprises a variety of fatty acids that act as a remarkable lipidic carbon source for induction of lipase production [15]. On the other hand, FWPH serves as a rich source of proteins aiding in the luxurious growth of organisms and metabolite production. Moreover, most of the protein supplements used for the cultivation of LAB are of bovine origin which makes it unsuitable for use in food industries $[26,27]$.

3.2. Screening of Significant Independent Parameters by Factorial Design. The observed lipase activity values are shown in Table 2 along with the experimental runs. The influence of the chosen independent parameters on lipase production by MTCC 5695 and MTCC 11361 was studied by a ( 5 factors * 2 levels) factorial design. ANOVA results for MTCC 5695 (Table 3(a)) and MTCC 11361 (Table 3(b)) indicate time $(X 3)$, FWPH concentration (X4), and FWO concentration $(X 5)$ to be the most significant independent parameters affecting lipase production $(P \leq 0.05)$. It was observed that time had a negative effect on lipase production, whereas FWO concentration and FWPH concentration had a positive effect. The production of lipase by MTCC $5695\left(Y_{1}\right)$ and MTCC
TABLE 3: (a) ANOVA table for lipase activity of MTCC 5695 as affected by $\mathrm{pH}$, temperature, time, FWPH concentration, and FWO concentration. (b) ANOVA table for lipase activity of MTCC 11361 as affected by $\mathrm{pH}$, temperature, time, FWPH concentration, and FWO concentration.

(a)

\begin{tabular}{|c|c|c|c|c|c|}
\hline & SS & df & MS & $F$ & $P^{*}$ \\
\hline \multicolumn{6}{|c|}{ Independent interactions } \\
\hline $\mathrm{pH}$ & 69276.12 & 1 & 69276.12 & 3.39826 & 0.077 \\
\hline TEMP & 79015.43 & 1 & 79015.43 & 3.876011 & 0.059 \\
\hline TIME & 707949.5 & 1 & 707949.5 & 34.72765 & $3.25 E-06$ \\
\hline FWPH & 677272.3 & 1 & 677272.3 & 33.22281 & $4.54 E-06$ \\
\hline FWO & 1665495 & 1 & 1665495 & 81.69894 & $1.66 E-09$ \\
\hline Error & 530029.8 & 26 & 20385.76 & & \\
\hline Total SS & 3729038 & 31 & & & \\
\hline
\end{tabular}

${ }^{*}$ Values less than 0.05 indicate significance at $95 \%$ confidence interval.

(b)

\begin{tabular}{lccccc}
\hline & SS & df & MS & $F$ & $P^{*}$ \\
\hline \multicolumn{5}{c}{ Independent interactions } \\
\hline pH & 1930.3 & 1 & 1930.3 & 1.12393 & 0.299 \\
TEMP & 571.212 & 1 & 571.212 & 0.33259 & 0.569 \\
TIME & 24244.4 & 1 & 24244.4 & 14.1165 & 0.0008 \\
FWPH & 15280.4 & 1 & 15280.4 & 8.89709 & 0.0061 \\
FWO & 326049 & 1 & 326049 & 189.844 & $1.8 E-13$ \\
Error & 44653.9 & 26 & 1717.46 & & \\
\hline Total SS & 412729 & 31 & & &
\end{tabular}

*Values less than 0.05 indicate significance at 95\% confidence interval.

$11361\left(Y_{2}\right)$ as a function of these parameters is represented by the following:

$$
\begin{aligned}
Y_{1}= & -192.935+46.528 * X 1+9.938 * X 2 \\
& -6.19748 * X 3+2909.623 * X 4+114.0688 * X 5, \\
Y_{2}= & -58.3232+7.766719 * X 1+0.844994 * X 2 \\
& -1.14688 * X 3+437.0406 * X 4+50.47033 * X 5 .
\end{aligned}
$$

The optimum levels of the significant independent parameters were determined further by a Box-Behnken design and the insignificant independent parameters, that is, $\mathrm{pH}(X 1)$ and temperature $(X 2)$ were maintained at the centre of their levels.

3.3. Optimization of Parameters for Lipase Production by BoxBehnken Design. The influence of FWO concentration $(X 1)$, FWPH concentration (X2), and time (X3) on lipase production was determined by Box-Behnken design as indicated in Table 4, which also presents the observed values for lipase activity of MTCC $5695\left(Y_{1}\right)$ and MTCC $11361\left(Y_{2}\right)$ at different combinations of the independent parameters. The lipase produced was found to vary from $437 \mathrm{U} / \mathrm{mL}$ to $1707 \mathrm{U} / \mathrm{mL}$ for MTCC 5695 and from $10.48 \mathrm{U} / \mathrm{mL}$ to $487.22 \mathrm{U} / \mathrm{mL}$ for MTCC 11361, in the fifteen experiments conducted which 
TABLE 4: Actual levels of independent variables with the observed values of the response variable, Lipase activity ( $Y_{1}$ of MTCC 5695 , $Y_{2}$ of PA-63).

\begin{tabular}{lccccc}
\hline Run \# & $X 1$ & $X 2$ & $X 3$ & $Y_{1}$ & $Y_{2}$ \\
\hline 1 & 1 & 0.1 & 48 & 598 & 10.48 \\
2 & 5 & 0.1 & 48 & 1128 & 255.47 \\
3 & 1 & 0.2 & 48 & 452 & 49.60 \\
4 & 5 & 0.2 & 48 & 1160 & 293.61 \\
5 & 1 & 0.15 & 24 & 437 & 214.96 \\
6 & 5 & 0.15 & 24 & 1707 & 487.22 \\
7 & 1 & 0.15 & 72 & 654 & 55.81 \\
8 & 5 & 0.15 & 72 & 977 & 387.92 \\
9 & 3 & 0.1 & 24 & 813 & 294.92 \\
10 & 3 & 0.2 & 24 & 799 & 346.98 \\
11 & 3 & 0.1 & 72 & 567 & 279.61 \\
12 & 3 & 0.2 & 72 & 667 & 434.99 \\
13 & 3 & 0.15 & 48 & 820 & 394.92 \\
14 & 3 & 0.15 & 48 & 829 & 396.32 \\
15 & 3 & 0.15 & 48 & 913 & 396.58 \\
\hline
\end{tabular}

$X 1$ : FWO concentration, $\% \mathrm{v} / \mathrm{v} ; X 2$ : FWPH concentration, $\mathrm{mg} / \mathrm{mL} ; X 3$ : time, hours.

$Y_{1}$ : lipase activity $(\mathrm{U} / \mathrm{mL})$ of MTCC 5695; $Y_{2}$ : lipase activity of MTCC 11361.

shows the strong influence of media components on the lipase production.

Tables 5(a) and 5(b) indicate the ANOVA table for MTCC 5695 and MTCC 11361, respectively. Table 5(a) presents that among the independent variables, quadratic effect of FWO and FWPH showed significance on the response variable, whereas only linear effect of time had significance $(P<0.05)$. Moreover, the interactions between factors did not significantly influence $(P \geq 0.05)$ lipase production by MTCC $5695\left(Y_{1}\right)$ except for the interaction between FWO and time. Table 5(b) depicts that among independent variables quadratic effect of FWO and FWPH showed significance on the response variable $(P<0.05)$, but both quadratic and linear effects of time did not show significance for lipase production by MTCC $11361\left(Y_{2}\right)$. Interactions between the independent variables did not show any significant effect $(P \geq 0.05)$. Similar studies stating the significant influence of sunflower oil and palm oil as inducible carbon sources on lipase production have been reported $[28,29]$.

The response surface graph for $Y_{1}$ and $Y_{2}$ as a function of FWPH concentration and FWO concentration is presented in Figures 1(a) and 1(c), respectively. It was observed that lipase production increased with increase in FWPH concentration up to $0.16 \mathrm{mg} / \mathrm{mL}$ beyond which there was a decrease in case of both the organisms probably due to inhibition of enzyme activity in the presence of excess nitrogen. A possible mechanism may be that FWPH is a complex nitrogen source and the cells may produce more protease for the degradation of FWPH before its utilization. This might result in lower production and higher degradation of the lipase [30]. The lipase production increased with increase in FWO concentration for MTCC 5695, whereas lipase production increased with increase in FWO concentration up to $4 \% \mathrm{v} / \mathrm{v}$
TABLE 5: (a) ANOVA Table for lipase activity of MTCC 5695 as affected by FWO concentration, FWPH concentration, and time. (b) ANOVA Table for lipase activity of MTCC 11361 as affected by FWO concentration, FWPH concentration, and time.

(a)

\begin{tabular}{|c|c|c|c|c|c|}
\hline & SS & Df & MS & $F$ & $P^{*}$ \\
\hline \multicolumn{6}{|c|}{ Independent variables } \\
\hline FWO $(L)$ & 1001820 & 1 & 1001820 & 177.0422 & $4.288 E-05$ \\
\hline FWO $(Q)$ & 41780.83 & 1 & 41780.83 & 7.383533 & 0.0412 \\
\hline FWPH $(L)$ & 98 & 1 & 98 & 0.017319 & 0.9004 \\
\hline FWPH (Q) & 58502.83 & 1 & 58502.83 & 10.33865 & 0.0236 \\
\hline TIME $(L)$ & 99235.12 & 1 & 99235.12 & 17.53689 & 0.0086 \\
\hline TIME (Q) & 1020.519 & 1 & 1020.519 & 0.180347 & 0.6887 \\
\hline \multicolumn{6}{|c|}{ Interactions } \\
\hline $1 * 2$ & 7921 & 1 & 7921 & 1.399804 & 0.2899 \\
\hline $1 * 3$ & 224202.3 & 1 & 224202.3 & 39.62116 & 0.0015 \\
\hline $2 * 3$ & 3249 & 1 & 3249 & 0.574165 & 0.4827 \\
\hline Error & 28293.25 & 5 & 5658.65 & & \\
\hline
\end{tabular}

Total SS $\quad 1474217 \quad 14$

*Values less than 0.05 indicate significance at $95 \%$ confidence interval.

(b)

\begin{tabular}{|c|c|c|c|c|c|}
\hline & SS & df & MS & $F$ & $P^{*}$ \\
\hline \multicolumn{6}{|c|}{ Independent variables } \\
\hline FWO $(L)$ & 149431.7 & 1 & 149431.7 & 42.7161 & 0.0012 \\
\hline FWO (Q) & 81039.24 & 1 & 81039.24 & 23.16564 & 0.0048 \\
\hline FWPH $(L)$ & 10131.9 & 1 & 10131.9 & 2.896276 & 0.1495 \\
\hline FWPH $(Q)$ & 33675.83 & 1 & 33675.83 & 9.626472 & 0.0267 \\
\hline $\operatorname{TIME}(L)$ & 4312.883 & 1 & 4312.883 & 1.232868 & 0.3173 \\
\hline TIME (Q) & 5526.075 & 1 & 5526.075 & 1.579667 & 0.2643 \\
\hline \multicolumn{6}{|c|}{ Interactions } \\
\hline $1 * 2$ & 0.239121 & 1 & 0.239121 & $6.84 \mathrm{E}-05$ & 0.9937 \\
\hline $1 * 3$ & 895.5056 & 1 & 895.5056 & 0.255987 & 0.6344 \\
\hline $2 * 3$ & 2668.756 & 1 & 2668.756 & 0.762883 & 0.4223 \\
\hline Error & 17491.26 & 5 & 3498.252 & & \\
\hline Total SS & 303990.7 & 14 & & & \\
\hline
\end{tabular}

*Values less than 0.05 indicate significance at $95 \%$ confidence interval.

beyond which there was a decrease for MTCC 11361. The decrease in lipase production by MTCC 11361 beyond 4\% v/v of FWO concentration may be due to the reason that high concentrations of FWO have more incidence of long chain fatty acids which might have an inhibitory effect on lipase production [5]. However, MTCC 5695 was found to be more tolerant to FWO. The influence of time and FWO concentration on $Y_{1}$ and $Y_{2}$ is presented in Figures 1(b) and $1(\mathrm{~d})$, respectively. The figure clearly indicates that lipase production decreases with increase in time for MTCC 5695 however, a slight increase was observed after $48 \mathrm{~h}$ for MTCC 11361. This may be probably due to the fact that MTCC 5695 and MTCC 11361 achieve maximum growth in $24 \mathrm{~h}$ after which they enter the stationary phase resulting in a steady decline in lipase production. 


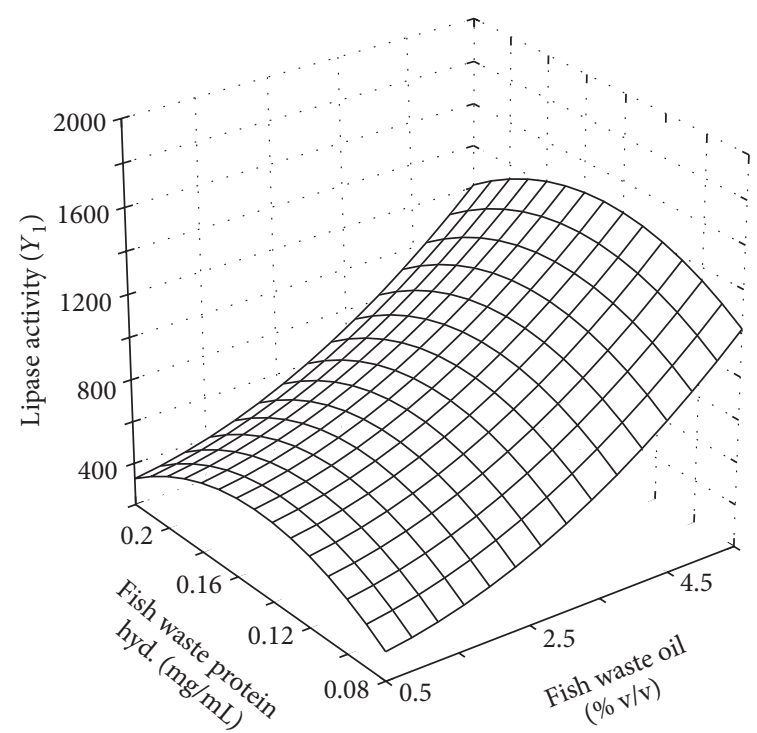

(a)

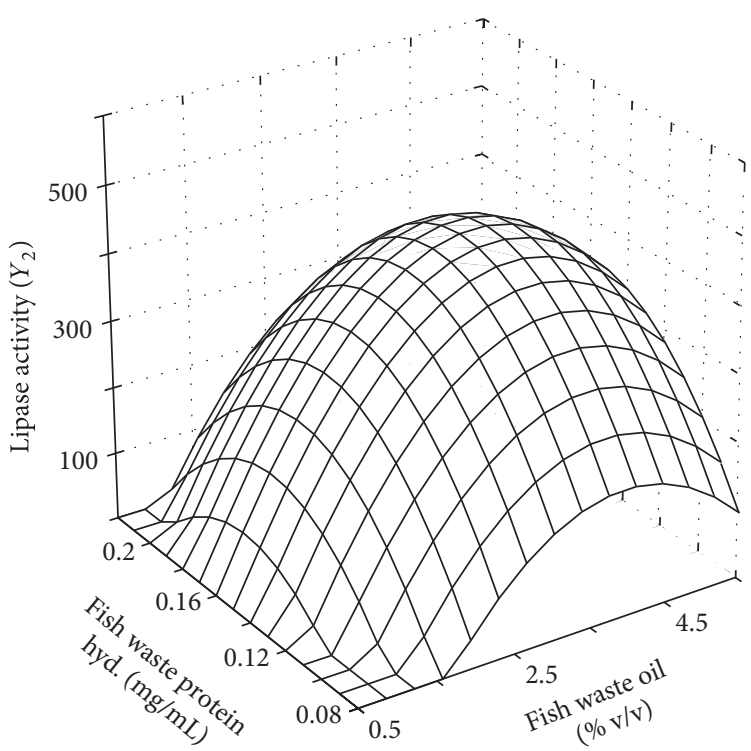

(c)

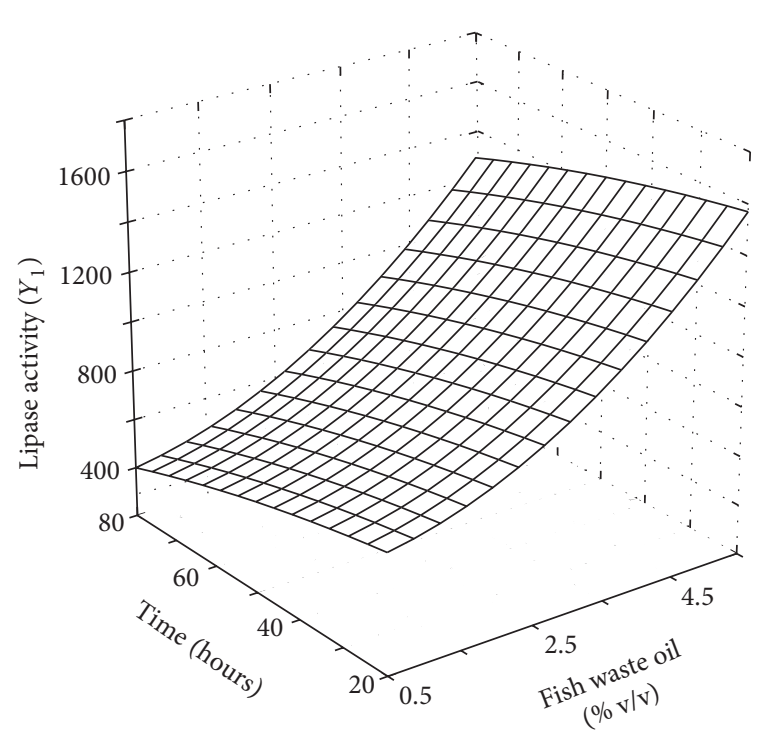

(b)

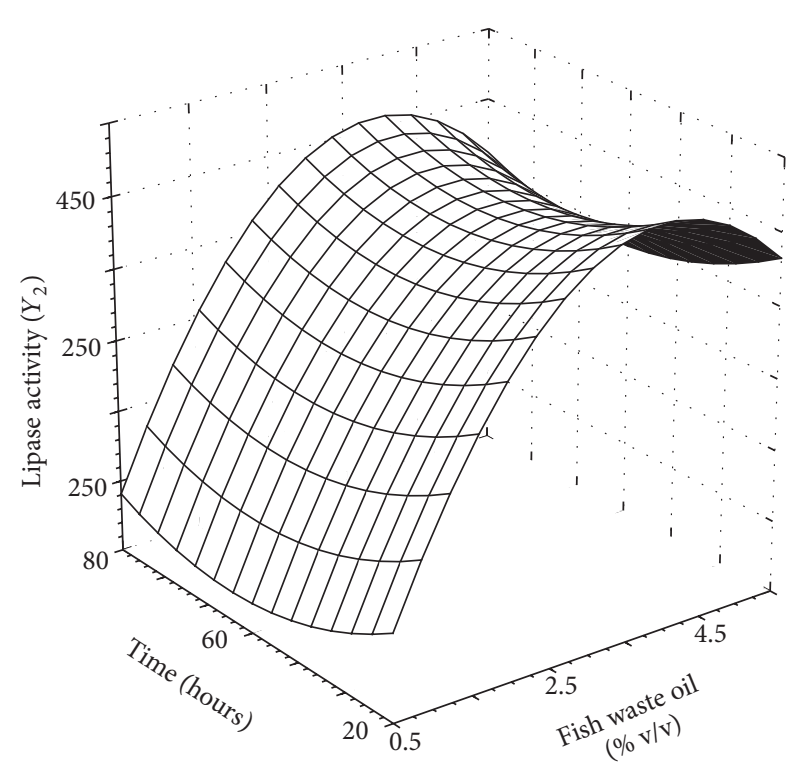

(d)

FIGURE 1: Three-dimensional plot showing the effect of: (a) FWPH concentration, FWO concentration; (b) FWO concentration, time; on lipase production by MTCC 5695 (c) FWPH concentration, FWO concentration; (d) FWO concentration, time; on lipase production by MTCC 11361. (FWPH: fish waste protein hydrolysates; FWO: fish waste oil).

The optimized levels of variables $(X 1, X 2$, and $X 3)$ were determined using desirability profiles for $Y_{1}$ and $Y_{2}$ (Figures $2(\mathrm{a})$ and $2(\mathrm{~b}))$. The optimized factors for obtaining the highest $Y_{1}$ were $5 \% \mathrm{v} / \mathrm{v}$ FWO concentration, $0.15 \mathrm{mg} / \mathrm{mL}$ FWPH concentration at $24 \mathrm{~h}$ of fermentation whereas for $Y_{2}, 4 \% \mathrm{v} / \mathrm{v}$ FWO concentration, $0.15 \mathrm{mg} / \mathrm{mL}$ FWPH concentration at $24 \mathrm{~h}$ of fermentation were found to be optimum. The response variables $Y_{1}$ and $Y_{2}$ were assigned a desirability of 1.0 for the highest observed value $\left(Y_{1}-1707 \mathrm{U} / \mathrm{mL}\right.$ and $Y_{2}-487.22 \mathrm{U} / \mathrm{mL}$ ) and a desirability of 0 for the lowest observed value $\left(Y_{1}-437 \mathrm{U} / \mathrm{mL}\right.$ and $\left.Y_{2}-10.48 \mathrm{U} / \mathrm{mL}\right)$ to get the overall desirability. The desirability function to get the optimum lipase production was fitted by the least square method. The level of variable giving the highest desirability (1.0) was selected as the optimum level.

The regression equation for lipase activity of MTCC 5695 and MTCC 11361, as a function of the three independent variables $(X 1, X 2$, and $X 3)$ and their linear and quadratic interactions, is represented by the following:

$$
\begin{aligned}
Y_{1}= & -742.6+187.4 * X 1+26.6 * X 1^{2}+12560.0 * X 2 \\
& +50350.0 * X 2^{2}+9.4 * X 3+445.0 * X 1 * X 2 \\
& -4.9 * X 1 * X 3+23.7 * X 2 * X 3
\end{aligned}
$$



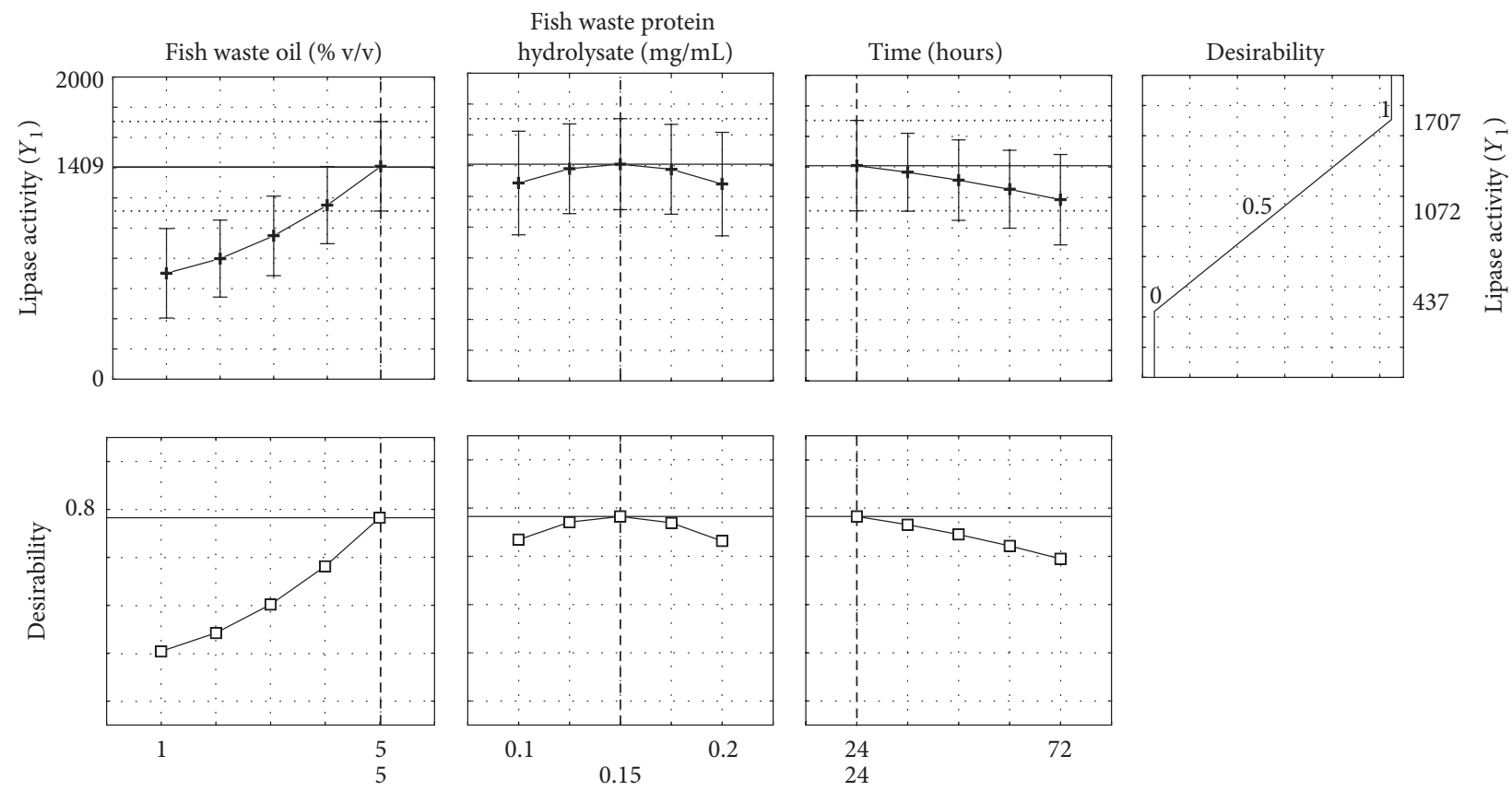

(a)

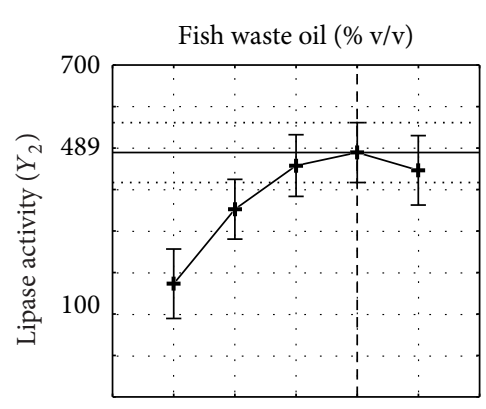

Fish waste protein hydrolysate $(\mathrm{mg} / \mathrm{mL})$
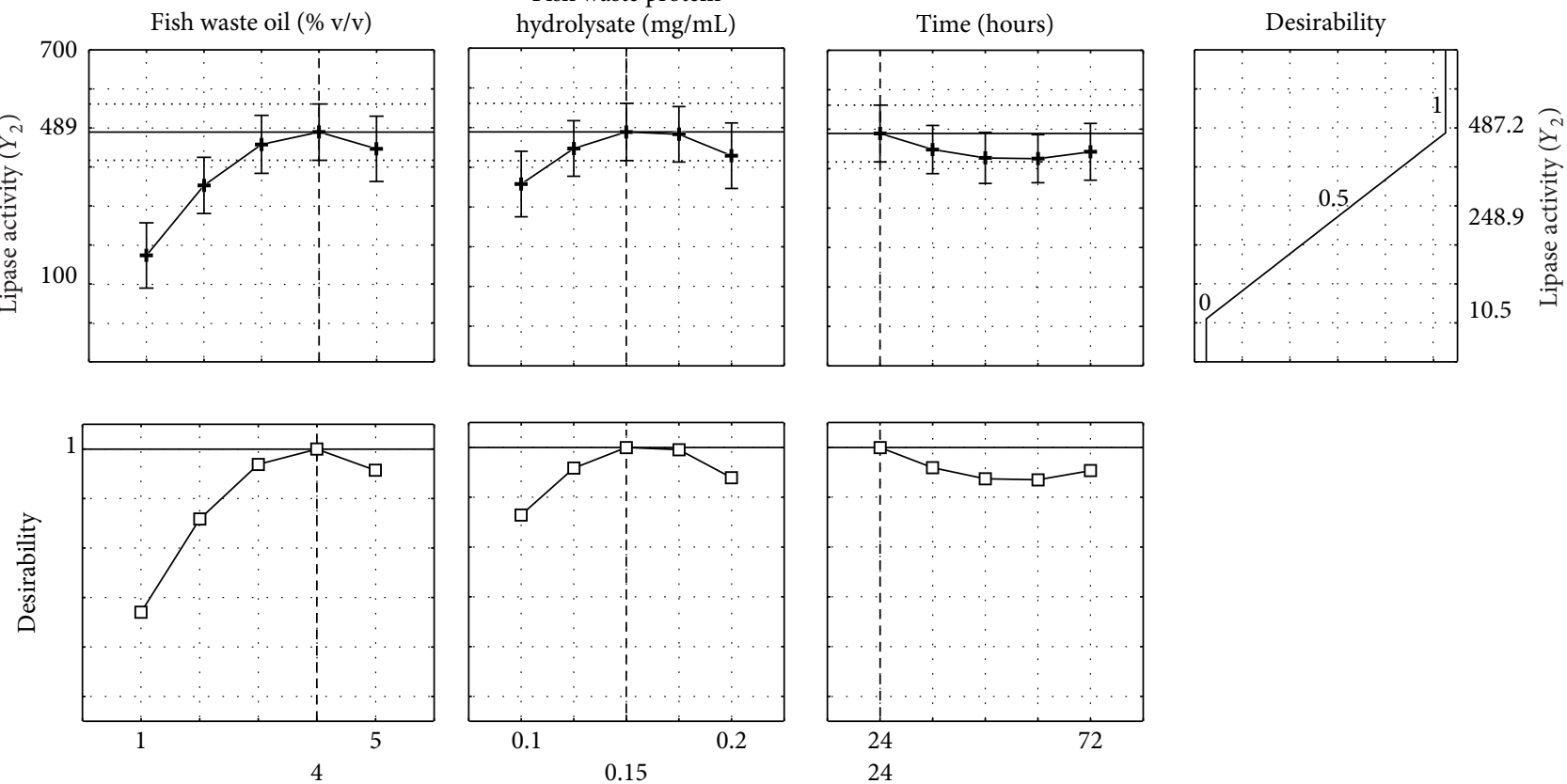

(b)

Figure 2: (a) Profiles for desirability levels of different factors (FWO-\% v/v; FWPH—\% v/v \& time/hours) for optimum lipase activity by Enterococcus faecium MTCC 5695 ( $\left.Y_{1}\right)$; (b) Profiles for desirability levels of different factors (FWO—\% v/v; FWPH—\% v/v \& time/hours) for optimum lipase activity by Pediococcus acidilactici MTCC $11361\left(Y_{2}\right)$.

$$
\begin{aligned}
Y_{2}= & -708.7+276.0 * X 1-37.0 * X 1^{2}+12560.0 * X 2 \\
& -38200.6 * X 2^{2}+0.1 * X 3^{2}-11.6 * X 3 \\
& -2.4 * X 1 * X 2+0.3 * X 1 * X 3+21.5 * X 2 * X 3 .
\end{aligned}
$$

Coefficient of determination $\left(R^{2}\right)$ is a measure of the strength of the linear relationship between the experimental and predicted values. $R^{2}$ for the correlation between the observed and predicted lipase activities of MTCC 5695 and MTCC 11361 was 0.9808 and 0.94246 , respectively. 
The model was validated by conducting experiments at $5 \% \mathrm{v} / \mathrm{v}$ FWO concentration, $0.15 \mathrm{mg} / \mathrm{mL}$ FWPH concentration at $24 \mathrm{~h}$ of fermentation for MTCC 5695 and $4 \% \mathrm{v} / \mathrm{v}$ FWO concentration, $0.15 \mathrm{mg} / \mathrm{mL}$ FWPH concentration at $24 \mathrm{~h}$ of fermentation for MTCC 11361. The experimental values of $Y_{1}(1715 \mathrm{U} / \mathrm{mL})$ and $Y_{2}(493 \mathrm{U} / \mathrm{mL})$ at these optimum conditions were quite close to the predicted values (1645.75 U/mL and $481.662 \mathrm{U} / \mathrm{mL}$, resp.) which indicated that the model was highly significant. A fold increase of 3.15 and 2.3 was obtained, respectively, in lipase production for MTCC 5695 and MTCC 11361 by optimization using RSM (i.e. lipase activity of $543.63 \mathrm{U} / \mathrm{mL}$ and $214.74 \mathrm{U} / \mathrm{mL}$ under unoptimized conditions, resp.). This fold increase is more than the fold increase obtained by Sharma et al. [31] wherein a 1.6-fold increase in lipase production was observed in Arthrobacter sp. BGCC\#490 and Kumari et al. [32] obtained 1.4-fold in lipase production in Enterobacter aerogenes under optimized conditions. Liu et al. [1] reported a 5-fold increase in lipase production by Burkholderia sp.

\section{Conclusion}

Enterococcus faecium MTCC 5695 and Pediococcus acidilactici MTCC 11361 were found to be potential lipaseproducing strains using fish waste substrates. RSM was found to be an efficient methodology for rapid optimization of influencing parameters and development of polynomial equation for lipase production. The significance of this work is that it includes the use of an economical substrate for lipase production, which in turn diminishes the problem of waste disposal from fish processing industries. Moreover, the optimized conditions obtained from this study can be used for large-scale cost-effective production of lipase from LAB.

\section{Acknowledgments}

B. Narayan thanks CSIR for funding this research work under the EMPOWER scheme (OLP 90). V. Ramakrishnan acknowledges the University Grants Commission (UGC) for the CSIR-UGC Fellowship. Authors place on record their thanks to the Director of CFTRI for permission to publish the work.

\section{References}

[1] C. H. Liu, W. B. Lu, and J. S. Chang, "Optimizing lipase production of Burkholderia sp. by response surface methodology," Process Biochemistry, vol. 41, no. 9, pp. 1940-1944, 2006.

[2] H. Treichel, D. D. Oliveira, M. A. Mazutti, M. D. Luccio, and J. V. Oliveira, "A review on microbial lipases production," Food and Bioprocess Technology, vol. 3, no. 2, pp. 182-196, 2010.

[3] D. Sharma, B. Sharma, and A. K. Shukla, "Biotechnological approach of microbial lipase: a review," Biotechnology, vol. 10, no. 1, pp. 23-40, 2011.

[4] F. Hasan, A. A. Shah, and A. Hameed, "Industrial applications of microbial lipases," Enzyme and Microbial Technology, vol. 39, no. 2, pp. 235-251, 2006.
[5] P. K. Ghosh, R. K. Saxena, R. Gupta, R. P. Yadav, and S. Davidson, "Microbial lipases: production and applications," Science progress, vol. 79, pp. 119-157, 1996.

[6] R. Gupta, N. Gupta, and P. Rathi, "Bacterial lipases: an overview of production, purification and biochemical properties," Applied Microbiology and Biotechnology, vol. 64, no. 6, pp. 763-781, 2004.

[7] R. K. Saxena, A. Sheoran, B. Giri, and W. S. Davidson, "Purification strategies for microbial lipases," Journal of Microbiological Methods, vol. 52, no. 1, pp. 1-18, 2003.

[8] S. A. Meyers, S. L. Cuppett, and R. W. Hutkins, "Lipase production by lactic acid bacteria and activity on butter oil," Food Microbiology, vol. 13, no. 5, pp. 383-389, 1996.

[9] M. R. F. Moreno, P. Sarantinopoulos, E. Tsakalidou, and L. De Vuyst, "The role and application of enterococci in food and health," International Journal of Food Microbiology, vol. 106, no. 1, pp. 1-24, 2006.

[10] T. Saito, "Selection of useful probiotic lactic acid bacteria from the Lactobacillus acidophilus group and their applications to functional foods," Animal Science Journal, vol. 75, no. 1, pp. 1-13, 2004.

[11] N. Thapa, J. Pal, and J. P. Tamang, "Phenotypic identification and technological properties of lactic acid bacteria isolated from traditionally processed fish products of the Eastern Himalayas," International Journal of Food Microbiology, vol. 107, no. 1, pp. 33-38, 2006.

[12] P. Sarantinopoulos, C. Andrighetto, M. D. Georgalaki et al., "Biochemical properties of enterococci relevant to their technological performance," International Dairy Journal, vol. 11, no. 8, pp. 621-647, 2001.

[13] M. F. S. Lopes, M. T. B. Crespo, A. E. Cunha, J. J. Clemente, and M. J. T. Carrondo, "Influence of environmental factors on lipase production by Lactobacillus plantarum," Applied Microbiology and Biotechnology, vol. 51, no. 2, pp. 249-254, 1999.

[14] FAO, Year Book of Fishery Statistics 2005, vol. 100-1/2, Food \& Agricultural Organization, Rome, Italy, 2010.

[15] A. K. Rai, H. C. Swapna, N. Bhaskar, P. M. Halami, and N. M. Sachindra, "Effect of fermentation ensilaging on recovery of oil from fresh water fish viscera," Enzyme and Microbial Technology, vol. 46, no. 1, pp. 9-13, 2010.

[16] M. Blanco, C. G. Sotelo, M. J. Chapela, and R. I. Pérez-Martín, "Towards sustainable and efficient use of fishery resources: present and future trends," Trends in Food Science and Technology, vol. 18, no. 1, pp. 29-36, 2007.

[17] A. K. Rai, N. Bhaskar, P. M. Halami, K. Indirani, P. V. Suresh, and N. S. Mahendrakar, "Characterization and application of a native lactic acid bacterium isolated from tannery fleshings for fermentative bioconversion of tannery fleshings," Applied Microbiology and Biotechnology, vol. 83, no. 4, pp. 757-766, 2009.

[18] N. M. Sachindra and N. Bhaskar, "In vitro antioxidant activity of liquor from fermented shrimp biowaste," Bioresource Technology, vol. 99, no. 18, pp. 9013-9016, 2008.

[19] D. Bas and I. H. Boyaci, "Modeling and optimization I: usability of response surface methodology," Journal of Food Engineering, vol. 78, no. 3, pp. 836-845, 2007a.

[20] D. Bas and I. H. Boyaci, "Modeling and optimization II: comparison of estimation capabilities of response surface methodology with artificial neural networks in a biochemical reaction," Journal of Food Engineering, vol. 78, no. 3, pp. 846-854, 2007 b. 
[21] N. Bhaskar, T. Benila, C. Radha, and R. G. Lalitha, "Optimization of enzymatic hydrolysis of visceral waste proteins of Catla (Catla catla) for preparing protein hydrolysate using a commercial protease," Bioresource Technology, vol. 99, no. 2, pp. 335-343, 2008.

[22] A. G. Gornall, C. J. Bardawill, and M. M. David, "Determination of serum proteins by means of the biuret reaction," The Journal of Biological Chemistry, vol. 177, no. 2, pp. 751-766, 1949.

[23] Y. Wang, J. Zhao, J. H. Xu et al., "Significantly improved expression and biochemical properties of recombinant serratia marcescens lipase as robust biocatalyst for kinetic resolution of chiral ester," Applied Biochemistry and Biotechnology, vol. 162, no. 8, pp. 2387-2399, 2010.

[24] Statsoft, Statistics For Windows, Statsoft, Tulsa, Okla, USA, 1999.

[25] R. Safari, A. Motamedzadegan, M. Ovissipour, J. M. Regenstein, A. Gildberg, and B. Rasco, "Use of hydrolysates from Yellowfin Tuna (Thunnus albacares) heads as a complex nitrogen source for lactic Acid Bacteria," Food and Bioprocess Technology, vol. 5, no. 1, pp. 73-79, 2009.

[26] J. A. Vázquez, M. I. Montemayor, J. Fraguas, and M. A. Murado, "Hyaluronic acid production by Streptococcus zooepidemicus in marine by-products media from mussel processing wastewaters and tuna peptone viscera," Microbial Cell Factories, vol. 9, article $46,2010$.

[27] S. J. Horn, S. I. Aspmo, and V. G. H. Eijsink, "Growth of Lactobacillus plantarum in media containing hydrolysates of fish viscera," Journal of Applied Microbiology, vol. 99, no. 5, pp. 1082-1089, 2005.

[28] Ü. Açikel, M. Erşan, and Y. Acıkel, "Optimization of critical medium components using response surface methodology for lipase production by Rhizopus delemar," Food and Bioproducts Processing, vol. 88, no. 1, pp. 31-39, 2010.

[29] P. Rathi, V. K. Goswami, V. Sahai, and R. Gupta, "Statistical medium optimization and production of a hyperthermostable lipase from Burkholderia cepacia in a bioreactor," Journal of Applied Microbiology, vol. 93, no. 6, pp. 930-936, 2002.

[30] G. Immanuel, P. Esakkiraj, A. Jebadhas, P. Iyapparaj, and A. Palavesam, "Investigation of lipase production by milk isolate Serratia rubidaea," Food Technology and Biotechnology, vol. 46, no. 1, pp. 60-65, 2008.

[31] A. Sharma, D. Bardhan, and R. Patel, "Optimization of physical parameters for lipase production from Arthrobacter sp. BGCC\#490," Indian Journal of Biochemistry and Biophysics, vol. 46, no. 2, pp. 178-183, 2009.

[32] A. Kumari, P. Mahapatra, and R. Banerjee, "Statistical optimization of culture conditions by response surface methodology for synthesis of lipase with Enterobacter aerogenes," Brazilian Archives of Biology and Technology, vol. 52, no. 6, pp. 1349-1356, 2009. 

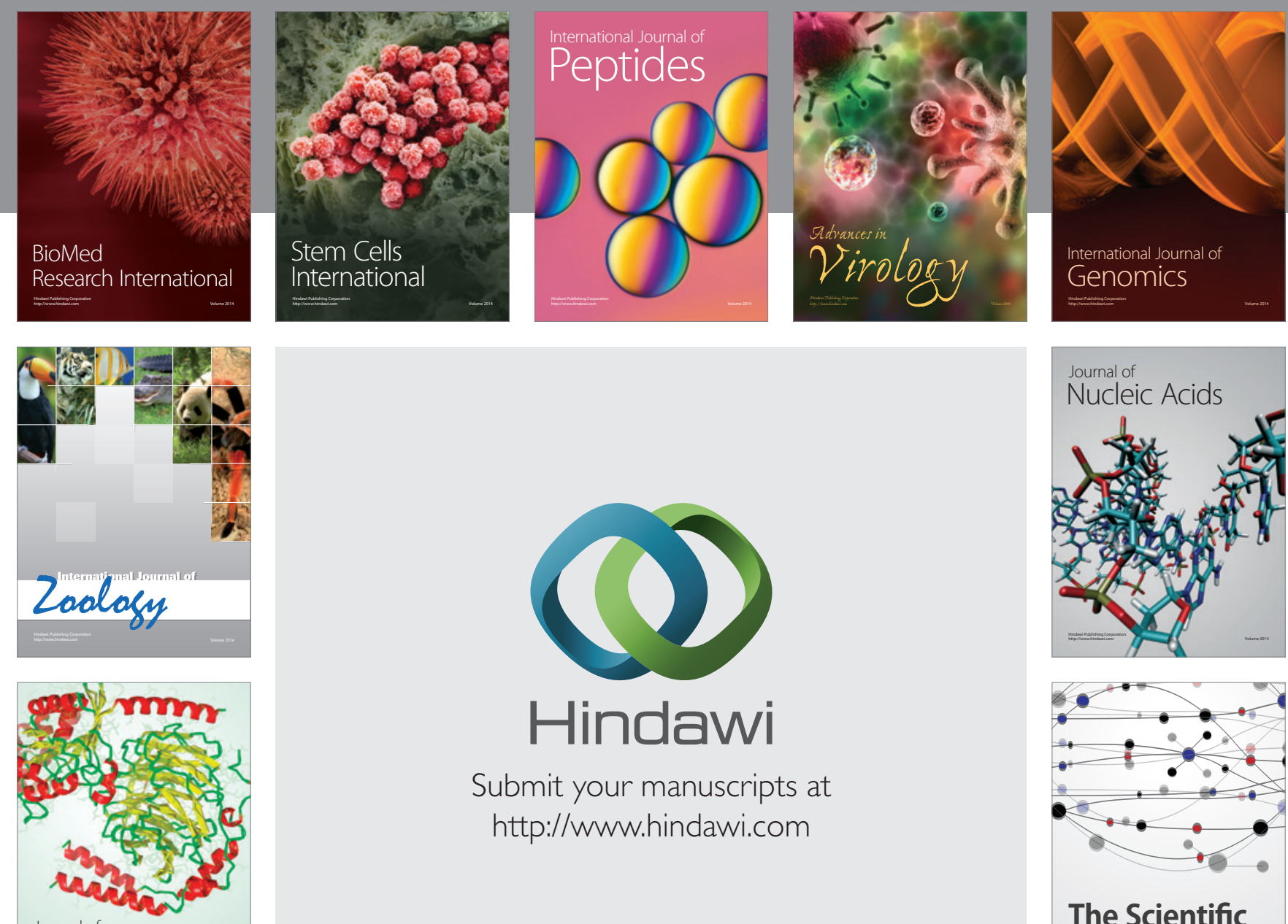

Submit your manuscripts at

http://www.hindawi.com

Journal of
Signal Transduction
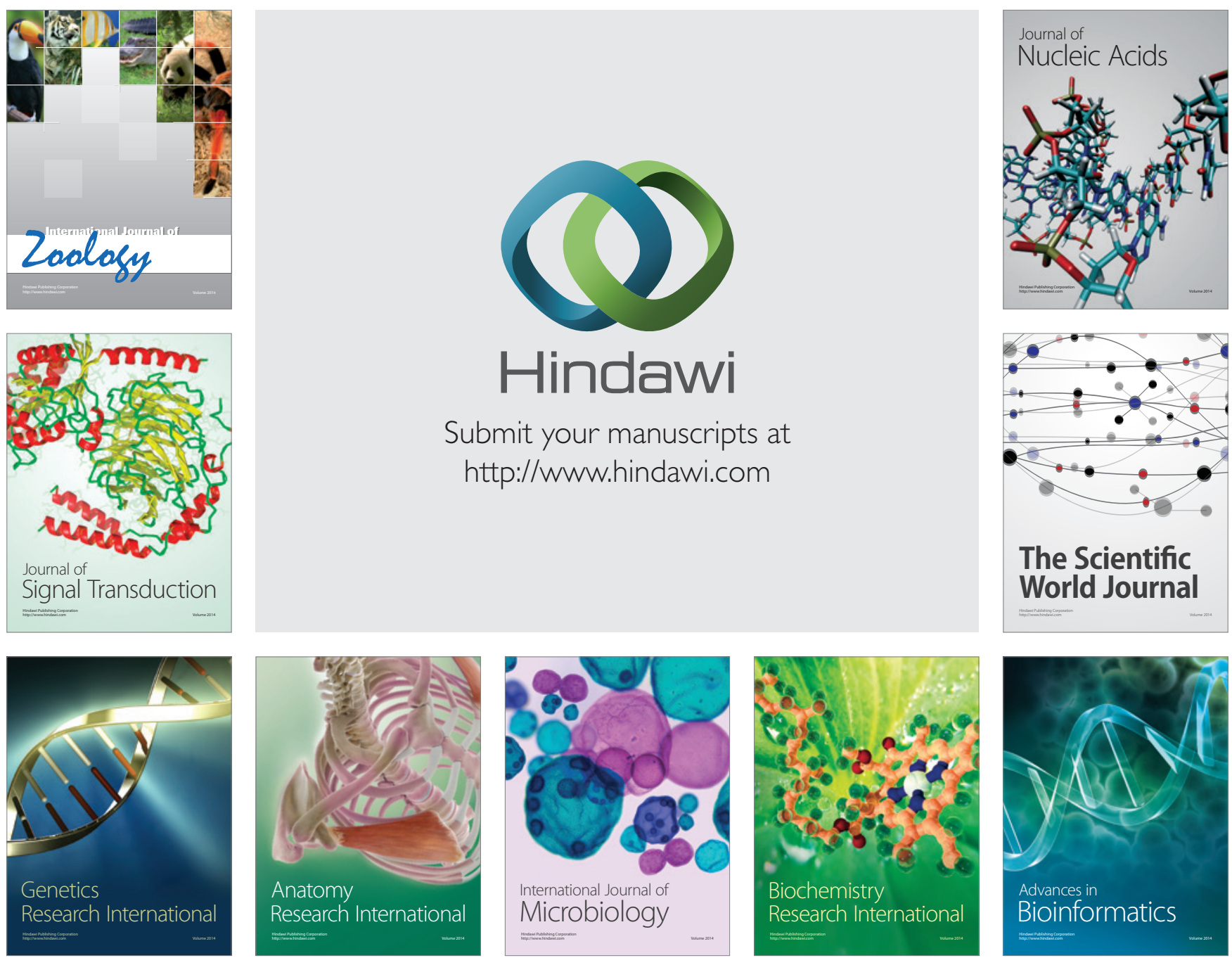

The Scientific World Journal
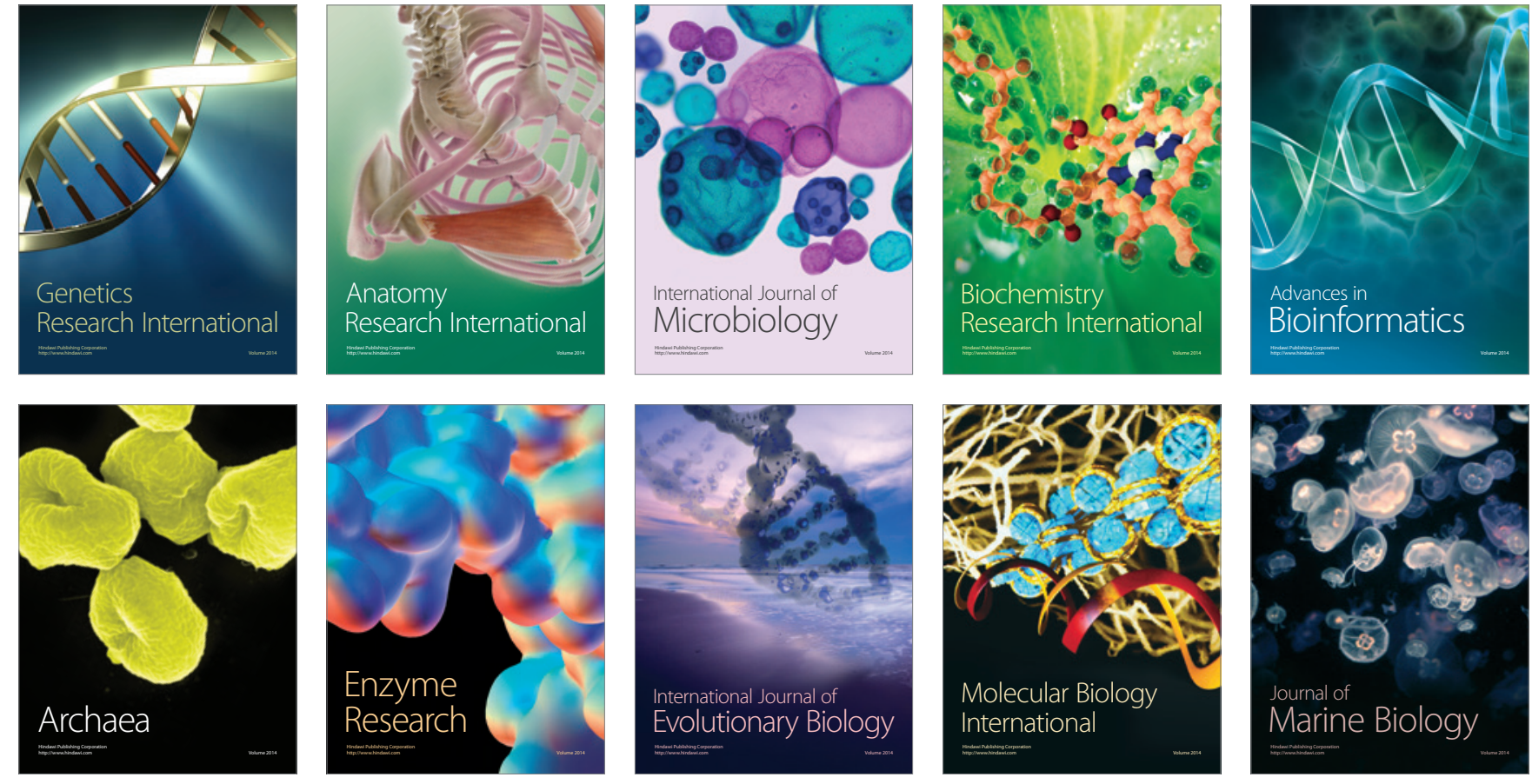